\title{
Ovarian inactivity in female dromedary camels
}

\author{
Nabil Mansour ${ }^{1,2 *}$ Aly Karen ${ }^{2}$ \\ ${ }^{1}$ Al-Taiba Farms, Raibal Co., Al-Mayya Group, Al Hilal Tower 3003, P.O. Box 666, Fujairah, UAE, ${ }^{2}$ Department of Theriogenology, Faculty of \\ Veterinary Medicine, Kafrelsheikh University, Egypt
}

A B S TR A C T

The present study describes a clinical trial aimed at understanding the causes of ovarian inactivity among female dromedary racing camels in the United Arab Emirates. A total of 1406 female racing camels were presented to the Aljazeera Veterinary Center during a 19-month period from September 2014 to April 2016 because of repeat breeding (as identified by camel owners). Females underwent ultrasonographic examination of the reproductive tract, as well as a manual vaginal examination. Any observed reproductive tract abnormalities were record. A percentage of 23.8 of females possessed no detectable reproductive tract abnormalities (and thus were diagnosed as typical repeat breeders). Of the remaining $76.2 \%$ of females, $59 \%$ had utero-tubal abnormalities and $41 \%$ had ovarian affections. The incidences of ovarian and utero-tubal affections in nulliparous and parous infertile females were $66.7 \%$ versus $33.3 \%(P<0.05)$ and $32.2 \%$ versus $67.8 \%(P<0.05)$, respectively. Most of the ovarian affections were due to ovarian inactivity or ovario-hydrobursitis. The incidence of ovarian inactivity and ovarian hydrobursitis in nulliparous and parous females were $57.6 \%$ versus $13.2 \%(P<0.05)$ and $5.8 \%$ versus $18.1 \%(P<0.05)$, respectively. A subset of animals lacking ovarian activity $(n=81)$ and cyclic control females $(n=24)$ underwent blood sample collection. Samples were analyzed for concentrations of red blood cells, hemoglobin, total protein, copper, glucose, calcium, iron, and phosphorus. Blood concentrations of glucose were higher and blood concentrations of copper were lower in females with inactive ovaries compared with cyclic females. After exclusion of animals with poor general health, the remaining females that did not have ovarian activity $(n=239)$ were divided into one of three treatment groups: Group $1(n=71)$ received a single treatment of subcutaneous copper and intramuscular multivitamins, plus daily intravenous infusion of phosphorous for 5 days and oral minerals and vitamins daily for 7 days; Group $2(n=104)$ received a single intramuscular injection of 1500 IU of equine chorionic gonadotropin-eCG; Group $3(n=64)$ were treated identically to group 1 females with the exception of receiving a single intramuscular injection of 1500 IU of eCG at the end of the 7-day treatment period; Group 3 females exhibited a higher ovarian response to treatment than either Group 2 or Group 1 females which were different from one another. Conception rate was lower in Group 2 females than in Group 1 and group 3 females which were not different. Embryonic mortality was higher in Group 2 than in Group 1 and 3 females which were not different. A number of 20 females was a subset of Group 3 females who failed to respond to treatment, they were treated for 10 days with an intravaginal device containing progesterone followed by a single intramuscular injection of 1500 IU of equine chorionic gonadotropin given at intravaginal device removal. Out of these 20 cases, twelve cases $(60.0 \%)$ were positively responded and after natural mating, nine female camels (45.0\%) were got pregnant. In conclusion, supplementation with multivitamins and mineral for a week followed by injection of 1500 IU eCG or using of intravaginal device CIDR for 10 days followed by injection of 1500 IU eCG are reliable protocols to treat the problem of ovarian inactivity in dromedary camels during breeding season.

Keywords: Dromedary camel; Infertility; Ovarian inactivity

\section{INTRODUCTION}

Reproductive performance in dromedary camels under natural conditions is low in comparison to other domestic animals (Kaufmann, 2005) due to delayed puberty, short breeding season, long gestation of 13 months and prolonged post-partum ovarian inactivity (Skidmore, 2005). Ovarian activity in dromedary camel increases during the breeding season in winter and spring months and depends on good food resources, climate conditions and female body condition (Ainani et al.,2018; Gherissi et al. 2020). However, there are some studies to investigate the reproductive problems and to improve the reproductive efficacy in dromedaries (Ali et al., 2010; 2015 \& 2018, Skidmore et al., 2019), ovarian inactivity phenomenon during the breeding season in camels has not been studied till now. Female camels suffering from ovarian inactivity are usually presented to the clinic with a history of several mating without conception or refuse mating (Ali et al. 2010). The reason of ovarian inactivity in female camels during the breeding season is still unknown and was attributed to the adverse body condition (Tibary and Anouassi, 1997; Gherissi et al. 2020). Insufficiency of production of gonadotropins from the anterior pituitary, failure of the ovaries to respond to gonadotropins, or improper nutrition are

\footnotetext{
${ }^{*}$ Corresponding author:

Nabil Mansour, Al-Taiba Farms, Raibal Co., Al Hilal Tower 3003, P.O. Box 666, Fujairah, United Arab Emirates. Tel: +971 506191799. E-mail: nabil@raibal.ae
} 
predisposing factors leading to ovarian inactivity (Hegazy et al., 2004). In camels, a decrease in gonadotropins level and increase in gonadal steroid levels are associated with ovarian inactivity and may explain the failure of the ovary to develop follicles (Hegazy et al., 2004). However, few studies were carried out to stimulate and monitor the ovarian activity either outside or at the beginning of the breeding season in dromedary camels with variable success (Agarwal et al., 1997; Quzy et al., 2013), no studies were done to overcome the problem of ovarian inactivity in female camels during the breeding season. The objectives of the current study were (a) a survey on the causes of infertility in female camels submitted to Aljazeera Veterinary Research Center, Al-Ain, UAE during two breeding seasons, (b) Determination of the incidence of ovarian inactivity in racing camels in UAE, either in nulliparous or parous females, (c) investigation of some blood parameters related to ovarian inactivity in female camels and (d) testing of some protocols to treat the problem of ovarian inactivity.

\section{MATERIAL AND METHODS}

\section{Animals and their management}

A total of 1406 racing female camels (72 nulliparous and 1334 pluriparous cows), aged between 4 to 20 yrs. old, were admitted to the clinic of Aljazeera Veterinary Center, Al Ain, United Arab Emirates during the period from September, 2014 to April, 2016. These females were presented with the history of repeat breeding without previous information about their keeping and feeding in their farms. In the center, the animals were kept in fenced pens, each pen contained 15 female camels, and fed on wheat bran, crushed maize, hay and dried alfalfa with a rate of $1.5,0.8,4.0$ and $2.0 \mathrm{Kg} /$ head/day.

\section{Gynecological examinations}

\section{Trans-rectal ultrasonography}

All females had been tranquilized by administration of xylazin 2\% (Alfasan, The Netherland) at a dose of 0.1 to $0.2 \mathrm{mg} / \mathrm{Kg} \mathrm{I} / \mathrm{V}$. The females were examined in the standing position by trans-rectal palpation and trans-rectal ultrasonography using MyLabFiveVet scanner (Esaote Europe B.V., Maastrich, Netherlands) or Ibex pro scanner (Medical Imaging, Colorado, USA). Both were equipped with $5-7.5 \mathrm{MHz}$ linear array endorectal transducers. The ovaries were scanned for the presence of different types of follicles, corpora lutae and any abnormal structures. The ovarian bursae and fallopian tubes were scanned for detection of ovarian hydrobursitis and hydro-salpinx, respectively. Uterine horns were scanned for the size, presence of abnormal fluid inside the lumen or any abnormal structures. Also, the mobility of the uterus and other parts of reproductive tract was evaluated by transrectal palpation.

\section{Vaginal examination:}

After cleaning with a mild antiseptic solution Betadine ${ }^{\circledR}$, the vulva was dried with cotton and wiped with $70 \%$ ethanol. Vaginal examination was carried by using Polansky vaginal speculum to detect the vaginal discharge, patency of the vagina and cervical canal.

\section{Definitions of different diagnostic cases Typical repeat breeder}

The females had been mated more than 3 times and on the clinical examinations and trans-rectal ultrasonography, there are no detectable abnormalities in the genital tract and the ovaries were normally cyclic.

\section{Specific causes of infertility Ovarian affections}

3.2.1.1. Ovarian inactivity was diagnosed by absence of any phase of follicular development on the ovaries (Fig. 1) at two successive examinations with an interval of 7-days. By trans-rectal palpation, clarification of inactive ovaries in female camels is not so easy and requires an experience to locate the ovary and identify such case (Tibary and Anouassi, 1997).

3.2.1.2. Ovarian bydrobursitis: The case was recognized by trans-rectal palpation when it was difficult to retract the uterus and a cord like structure was palpated between the ovarian end of the uterus and the corresponding ovaries. By Trans-rectal ultrasonography, the bursal fluid appears in most cases as clear anechoic fluid with different sizes, and in few cases, there are echogenic particles in the bursal fluid. In addition, the ovaries carrying different structures appears as floating mass (Fig. 2) in the bursal fluid (Tibary and Anouassi, 1997; Ali et al., 2011).

3.2.1.3. Other affections such as ovarian aplasia, hypoplasia and ovarian adhesions, with bursa, fallopian tube and sometimes extends to uterine horn, were diagnosed.

\section{Utero-tubal affections \\ 3.2.2.1. bydro-salpinx}

The uterine tube is filled with fluid, can be rectally palpated as tortuous distended structure near the ovary and by ultrasonography, it is demonstrated as many hypoechogenic well demarcated sacs adjacent to the ovary.

3.2.2.2. Clinical endometritis/cervicitis was diagnosed by slight enlargement of uterine horns by trans-rectal palpation and/ or observation of vaginal discharges by vaginal examination (Ali et al., 2010). 


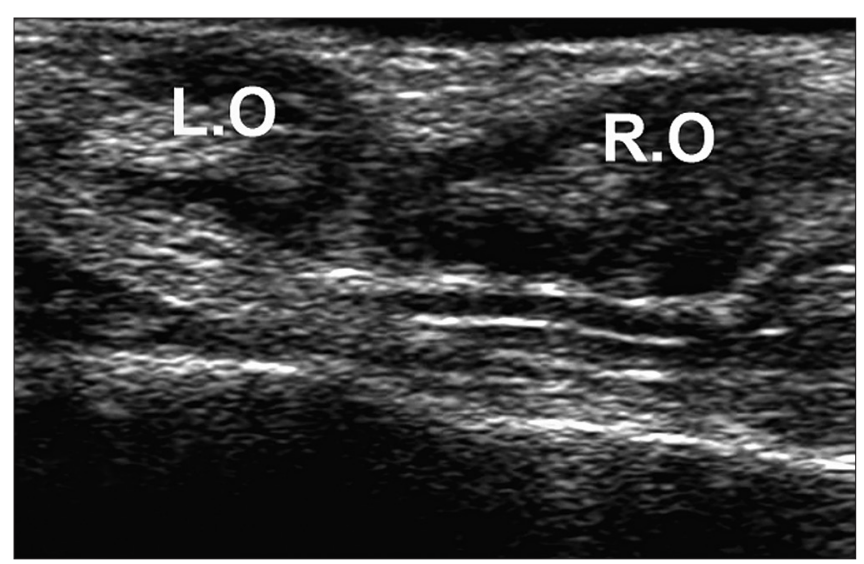

Fig 1. Ultrasound image shows a case of ovarian inactivity. R.O: right ovary; L.O: left ovary

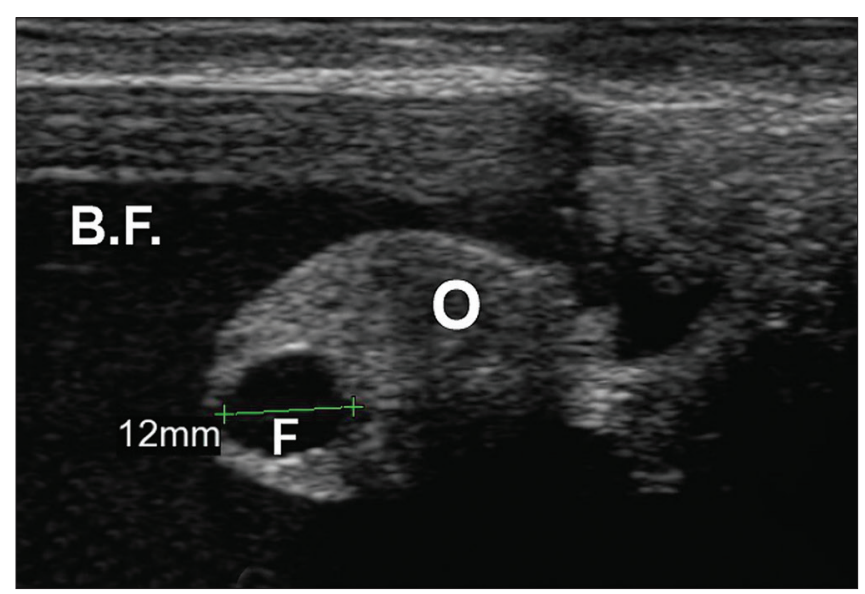

Fig 2. Ultrasound image shows a case of ovarian hydrobursitis. O: ovary; B.F: bursitis fluid; F: graafian follicle

3.2.2.3. Peri-uterine adhesions was diagnosed by rectal palpation as one or both uterine horns are not freely movable and attached to adjacent viscera.

3.2.2.4. Cervical and/or vaginal adhesions was diagnosed by vaginal examination where the access to the cranial part of the genital tract was blocked. This adhesion was found at mid or caudal vagina or the cervix. By transrectal ultrasonography, accumulation of hypo- or hyperechogenic materials in the uterus in most cases were detected.

\subsubsection{Imperforated bymen was detected through vaginal} examination of some heifers as a membrane cranial to the external opening of the urinary bladder.

\section{Measurements of blood parameters}

Blood samples were collected directly from the jugular vein of 81 females suffered from ovarian inactivity and a number of 24 cyclic females, as a control. Samples were collected throughout the two breeding seasons and before the onset of the treatment experiments. Blood samples were collected into EDTA and non EDTA sterile blood tubes and transferred to the laboratory. Blood cell counts were determined in EDTA tubes by using an automatic blood analyzer (Celltac $\alpha$ MEK-6450K, Nihon Kohden, Tokyo, Japan). The other tubes were centrifuged at $3000 \mathrm{rpm}$ for $10 \mathrm{~min}$ and the serum was collected. The serum levels of copper, glucose, calcium, total protein and phosphorus were determined by using an automatic analyzer for clinical chemistry and immunoturbidimetry (BT2000 Plus, Biotechnica Instruments, Rome, Italy).

\section{Treatment trials}

The emaciated animals with poor general health conditions $(n=25)$ were excluded from the treatment experiment and the remaining females suffered from ovarian inactivity $(n=234)$ were sub-divided into 3 groups and treated as follows:

Group 1: A number of 71 female camels were injected once with $5 \mathrm{ml}$ of $25 \mathrm{mg} / \mathrm{ml}$ copper S/C, (Cobremas, Zoo Vet Co., Argentina) and $20 \mathrm{ml}$ multivitamins I/M, (Norbrook ${ }^{\circledR}$ Laboratories Limited, Ireland)-Day 1, as a source for Vitamin A 300.000 IU, Vit D 500 mg, Vit E 400 mg, Vit B1 200 mg, Vit B2 100 mg, Vit B6 60 mg, Nicotinamide $700 \mathrm{mg}$, Pantothenol $500 \mathrm{mg}$ and Vit B12 $500 \mathrm{mg}$. Also, a daily injection of $3 \mathrm{~g}$ Butaphosphane $+1.5 \mathrm{mg}$ Vitamin B12 I/V (Metabol ${ }^{\circledR}$, WooGene BandG Co Ltd, Korea) for five successive days (Day 1-5) as a source for phorphorus and Vitamin B12. Additionally, $30 \mathrm{~g}$. of mineral and vitamin premix supplement which contains vitamins $A, D, E, B 1$, B2, B6, B12, C, niacin and pantothenic acid and minerals such as calcium, phosphorus, magnesium, iron, copper, cobalt, iodine, manganese, zinc and selenium $\left(\mathrm{Neomin}^{\circledR}\right.$, Shree Pharma Co., India) was orally administered daily for a period of a week (Day 1-7).

Group 2: A number of 104 were injected intramuscular with 1500 IU of eCG $\left(\right.$ Gonaser $^{\circledR}$, Laboratorios HIPRA S.A., Spain).

Group 3: A number of 64 female camels were treated for a week by the same treatment protocol of group 1 followed by injection with 1500 IU of eCG.

\section{Determination of the response of treatment}

All treated females were examined by trans-rectal ultrasonography one week after ending the treatment protocols and the follicular activity was recorded. Additionally, the trans-rectal ultrasonography was repeated every two days for another one week to follow up the status of the follicular development. Females showed a follicular activity and the follicles increased in size to reach $12-15 \mathrm{~mm}$ in diameter within 14 days after the end of the treatment protocol were considered positively 
responded. All the positively responded female camels were naturally mated within a maximum 16 days after ending the treatment protocols. Only three fertile males were used for the mating of all tested females. Fourteen days post-mating, blood samples were collected from jugular vein and serum was collected after centrifugation at $3000 \mathrm{rpm}$ for $10 \mathrm{~min}$. Progesterone concentration was measured by using P4-ELISA assay kit (Ridgeway Science, Alvington, UK). The sensitivity was $0.05 \mathrm{ng} / \mathrm{ml}$, and intra- and inter-assay precisions were $5.9 \%$ and $10.1 \%$, respectively. Female camels with a progesterone blood serum level of $>1.5 \mathrm{ng} / \mathrm{ml}$ were considered as conceived or pregnant (Nagy et al., 2005). Finally, at 45 days post-mating, the pregnant she-camels were examined by trans-rectal ultrasonography to calculated the rate of embryonic loss.

\section{Statistical analysis}

T-test followed by Tukey's test at a significance level of $P<0.05$ was used to compare the blood cell counts and serum biochemical analysis in-between the control cyclic female camels and those suffered from ovarian inactivity. Chi-square test was used to compare the incidence of infertility in nulliparous and parous female camels and significance was set at $P<0.05$. Also, the effect of different treatments on the reproductive performance rates (response, conception and pregnancy loss) were analyzed by $2 \mathrm{X} 4$ contingency table for chi-square hypothesis test procedures followed by with Yate's continuity correction whenever required. Response rate was calculated as the number of responded cases to the total treated animals. However, the conception rate was calculated as number of conceived cases after 14 days post-mating by serum P4 test to the total responded cases. Rate of embryonic mortalities was calculated as number of she-camels lost their pregnancy at 45 days post-mating to the total previously counted conceived cases. All statistical analyses were done using SPSS $^{\circledR} 22$ for Windows ${ }^{\circledR}$ (SPSS Worldwide Headquarters, Chicago, IL, USA).

\section{RESULTS}

Causes of infertility in female camels admitted to the center during the two breeding seasons is presented in Table 1. Typical repeat breeding females represented a total percentage of $23.8 \%$, while the females with clear clinical affections represented a total percentage of $76.2 \%$. The incidences of ovarian and utero-tubal affections in nulliparous and parous infertile females were $66.7 \%$ versus $33.3 \%(P<0.05)$ and $32.2 \%$ versus $67.8 \%(P<0.05)$, respectively (Table 1$)$. Most of the ovarian affections were due to ovarian inactivity or ovario-hydrobursitis. The incidences of ovarian inactivity and ovarian hydrobursitis in nulliparous and parous females were 57.6\% versus $13.2 \%(P<0.05)$ and $5.8 \%$ versus $18.1 \%(P<0.05)$ (Table 1). Ovario-hydrobursitis was detected unilateral in 13 cases of nulliparous females and 91 of parous females and bilateral in 3 cases of nulliparous and 53 of parous cases. While, the incidences of other ovarian affections such as ovarian aplasia, hypoplasia and ovarian adhesions were very low (Table 1).

Most of utero-tubal affections were due to clinical endometritis and/or cervicitis which were significantly higher in parous infertile females than nulliparous $(P<0.05)$. Peri-uterine adhesions, cervical and/or vaginal

Table 1: Incidence of infertility causes (number/percent) in female dromedary camels admitted to Aljazeera Veterinary Research Center

\begin{tabular}{|c|c|c|c|}
\hline Causes of infertility & Nulliparous $n=338$ & Parous $\mathrm{n}=1068$ & Total $n=1406$ \\
\hline A-Typical repeat breeder & $62(18.3)$ & $273(25.6)$ & $335(23.8 \%)$ \\
\hline B-Genital affections & $276(81.7)$ & $795(74.4)$ & $1071(76.2 \%)$ \\
\hline \multicolumn{4}{|l|}{ 1-Ovarian affections } \\
\hline Ovariab inactivity & $159(57.6)$ & $105(13.2)$ & $264(24.6)$ \\
\hline Ovarian hydrobursitis & $16(5.8)$ & $144(18.1)$ & $160(14.9)$ \\
\hline Ovarian aplasia & $5(1.8)$ & $0(0.0)$ & $5(0.5)$ \\
\hline Ovarian hypoplasia & $4(1.4)$ & $0(0.0)$ & $4(0.4)$ \\
\hline Ovarian adhesion & $0(0.0)$ & $7(0.9)$ & $7(0.7)$ \\
\hline Subtotal & $184(66.7)$ & $256(32.2)$ & $440(41.1)$ \\
\hline \multicolumn{4}{|l|}{ 2-Utero-tubal affections } \\
\hline Hydro-salpinx & $1(0.4)$ & $7(0.9)$ & $8(0.7)$ \\
\hline Cinical endometritis/cervicitis & $88(31.9)$ & $424(53.3)$ & $512(47.8)$ \\
\hline Pre-uterine adhesions & $0(0.0)$ & $67(8.4)$ & $67(6.3)$ \\
\hline Uterus unicornis & $2(0.7)$ & $1(0.1)$ & $3(0.3)$ \\
\hline Cervical/vaginal adhesions & $0(0.0)$ & $29(3.6)$ & $29(2.7)$ \\
\hline Imperforated hymen & $1(0.4)$ & $0(0.0)$ & $1(0.1)$ \\
\hline Vaginal (perineal) tear & $0(0.0)$ & $11(1.4)$ & $11(1.0($ \\
\hline Subtotal & 92 (33.3) & $539(67.8)$ & $631(59.0)$ \\
\hline
\end{tabular}


adhesions, and vaginal tears were only detected in parous females. Hydrosalpinx was detected in low percentages in nulliparous and parous females. Imperforated hymen was detected in only one nulliparous female (Table1).

Females suffered from ovarian inactivity, showed a significant decrease $(P<0.05)$ in copper concentration and increase in glucose $(P<0.05)$ concentration in comparison to the control cyclic females (Table 2). Females with ovarian inactivity showed no changes in the RBCs count, haemoglobin concentration and serum concentrations of total protein, calcium, iron and phosphorus compared to those of control group (Table 2).

Regarding the treatment of ovarian inactivity, the response rate was significantly lower $(P<0.05)$ in Group1 compared to those in Group 2, and Group 3 (Table 3). Moreover, the response rate was significantly higher $(P<0.05)$ in Group 3 compared to Group 2. However, there was no significant difference between the conception rate in between all three treated groups (Table 3), the rate of embryonic mortality at 45 days post-mating, was significantly lower $(P<0.05)$ in group1 compared to Group 2 (Table 3).

\section{DISCUSSION}

In the present study, $23.8 \%$ of the infertile females admitted to the center were typical repeat breeding without any

\begin{tabular}{|c|c|c|}
\hline Blood parameter & $\begin{array}{c}\text { Control cyclic } \\
(n=24)\end{array}$ & $\begin{array}{c}\text { Ovarian inactive } \\
(n=81)\end{array}$ \\
\hline Copper ( $\mu \mathrm{g} / \mathrm{dl})$ & $73.9 \pm 9.4^{a}$ & $62.0 \pm 10.6^{b}$ \\
\hline Glucose (mg/dl) & $121.7 \pm 13.0^{a}$ & $137.9 \pm 8.8^{b}$ \\
\hline RBC $\left(10^{6} / \mu \mathrm{l}\right)$ & $9.0 \pm 1.0^{\mathrm{a}}$ & $8.6 \pm 1.3^{\mathrm{a}}$ \\
\hline HGB $(g / l)$ & $12.2 \pm 1.2^{\mathrm{a}}$ & $12.0 \pm 2.0^{a}$ \\
\hline Total protein (g/dl) & $6.2 \pm 0.4^{a}$ & $5.9 \pm 0.7^{a}$ \\
\hline Calcium (mg/dl) & $8.9 \pm 0.4^{\mathrm{a}}$ & $8.5 \pm 1.0^{\mathrm{a}}$ \\
\hline Iron $(\mu \mathrm{g} / \mathrm{dl})$ & $85.1 \pm 16.4^{a}$ & $87.8 \pm 13.1^{\mathrm{a}}$ \\
\hline Phosphorus (mg/dl) & $4.1 \pm 1.4^{\mathrm{a}}$ & $4.2 \pm 1.5^{\mathrm{a}}$ \\
\hline
\end{tabular}

Values within rows with different super superscripts are significantly different $(P<0.05)$ detectable genital affections. Subclinical endometritis, lacking of ovulatory follicles with subsequent improper mating time or male factor such as infertile, low fertile, or male exhaustion, might be the cause of this phenomenon (Tibary and Anouassi, 1997). Also, early embryonic death due to genetic or environmental factors, corpus luteum dysfunction could contribute and increase the incidence of this phenomenon (Tibary and Anouassi, 2000). Incidence and pathogenesis of different genital affections, either ovarian or utero-tubal affections, in dromedary camels were previously discussed in details (For reviews: Tibary and Anouassi, 1997; Tibary, 2004; Ali et al., 2010; 2015 \& 2018).

To date, ovarian inactivity during breeding season in dromedary camels has not been studied in details. Many causes can contribute to the occurrence of such problem such as nutritional, managemental and/or hormonal reasons (Hegazy et al., 2004) and is greatly affected by the body condition, lactation and use of the animal (Tibary and Anouassi, 2000). Nowadays, camels are kept in captivity, in pens separating the males from females, and depraved from grazing and feeding on their natural desert plants which might affect negatively the reproductive physiology. In our study, the incidence of ovarian inactivity during breeding season was higher in nulliparous infertile females which might be due to low body condition score shortly after racing (Gherissi et al. 2020).

This is the first study conducted on ovarian inactivity in female camels during reproductive season in aspect of blood parameters and the possibilities of treatment. Our results showed that camels suffered from ovarian inactivity had a lower serum concentration of copper and higher concentration of glucose. In bovine, copper plays an important role in oocyte maturation and early embryonic development (Piccoa et al., 2012). Also, copper deficiency causes oxidative stress to buffalo-cows resulting in cessation of ovarian activity (Ahmed et al., 2009). Copper is considered an important trace element supports the reproductive performance in camels and its deficiencies might results in infertility (Zaher et al., 2017). The interpretation for the increase in blood glucose level in cases of ovarian inactivity in our study is unknown.

Table 3: Effect of different treatment protocols on the response rate, conception rate at 14 days post-mating and rate of embryonic mortalities at $\mathbf{4 5}$ days post-mating in ovarian inactive female dromedary camels

\begin{tabular}{|c|c|c|c|}
\hline \multirow[t]{2}{*}{ Evaluating criteria } & Group 1 & Group 2 & Group 3 \\
\hline & $n=71$ & $\mathrm{n}=104$ & $\mathrm{n}=64$ \\
\hline Response rate (No. of animals responded/animals treated) & $54.8 \%(57 / 104)^{\mathrm{b}}$ & $39.4 \%(28 / 71)^{a}$ & $82.8 \%(53 / 64)^{c}$ \\
\hline Conception rate (No. of animals conceived/animals responded) & $45.5 \%(15 / 33)^{\mathrm{a}}$ & $58.8 \%(10 / 17)^{\mathrm{a}}$ & $56.3 \%(18 / 32)^{\mathrm{a}}$ \\
\hline $\begin{array}{l}\text { Rate of embryonic mortalities (No. of animals lost their } \\
\text { pregnancies/total conceived animals) }\end{array}$ & $26.6 \%(4 / 15)^{b}$ & $10.0 \%(1 / 10)^{a}$ & $16.6 \%(3 / 18)^{a, b}$ \\
\hline
\end{tabular}

Values within rows with different super superscripts are significantly different $(P<0.05)$

Group 1: received multivitamins, copper and phosphorus

Group 2: treated with 1500 IU of eCG

Group 3: received multivitamins, copper and phosphorus for a week followed by 1500 IU of eCG 
In a previous study, serum glucose level was significantly decreased in infertile female camels without a clear identification of real cause of infertility (Zaher et al., 2017). In cows, blood glucose concentration is inversely related to milk production and significantly increased before calving (Kappel et al., 1984).

Serum concentrations of calcium, iron, phosphorus and total protein did not change in female camels with ovarian inactivity than those of normal cyclic ovaries. Similar to the study of Zaher et al. (2017), the concentration of iron, sodium, potassium and chloride did not decrease in smooth inactive camels compared to clinically healthy ones. However, pregnant female camels showed lower concentrations of calcium, phosphorus, iron and total protein than non-pregnant females (Saeed et al., 2009).

Our results showed that the best response rate of females with ovarian inactivity was detected in group 3 which received copper, phosphorus and multivitamins supplementations for one week followed by injection of 1500 IU eCG. This indicating that, ovarian inactivity in female camels was due to nutritional factors and/ or with hormonal factors similar to other species (Tibary and Anouassi, 2000). In our study, 47 out of 104 (45.2\%) females suffered from ovarian inactivity (Group 2) during breeding season, did not respond to injection of $1500 \mathrm{IU}$ eCG alone. When this hormonal treatment was primed with multivitamins, copper and phosphorus injections for one week, as in group 3 , the response rate was increased to $82.8 \%$. Indicating that ovarian inactivity in current study is not only due to hormonal factors, but also due to other nutritional and some managemental factors (Tibary and Anouassi, 2000). Malnutrition might decrease production of gonadotropins from pituitary gland or decrease the ovarian response to released gonadotropins leading to ovarian inactivity (Butler and Smith, 1989, Hegazy et al., 2004). In some previous studies, equine chorionic gonadotropin (eCG) in a dose of 1000-3000 IU was used to induce estrus in camels during the non-breeding season with a variable response of follicular development and pregnancy rate (Elias et al.,1985; Agarwal et al., 1997; Khalid and Al-Sobayil, 2008). Also, during early breeding season administration of $2000 \mathrm{IU}$ eCG in female camels showed a response of $79.1 \%$ evidenced with mature follicles and a pregnancy rate of $65.1 \%$ after natural mating (Quzy, et al., 2013).

A number of 20 females with ovarian inactivity did not respond to the protocol used for group 3 were treated with progesterone in the form of intravaginal device CIDR, each device contains $1.72 \mathrm{~g}$ progesterone (Cue-mare ${ }^{\circledR}$; Bioniche, Australia) for 5 days, replaced with a new CIDR for another 5 days and followed by injection of $1500 \mathrm{eCG}$. Out of these 20 cases, twelve cases $(60.0 \%)$ were positively responded, as a follicular development. After natural mating, nine female camels $(45.0 \%)$ were got pregnant. However, we can't compare the results of this group with the other 3 groups, in aspect of response rate, because these twenty animals did not respond to previously to both the multivitamins, copper and phosphorus supplementations alone or followed by eCG injection. Therefore, this protocol seems more promising for treating ovarian inactivity in female camels. Similar to other studies done outside the breeding season in dromedary camels, administration of progesterone, either by IM injection (Agarawal et al., 1997) or intra-vaginal device (CIDR) (Khalid and Al-Sobayil, 2008; Monaco et al., 2012) followed by injection of eCG increased the follicular development with estrus signs than the using of eCG alone. Also, camels treated with PRIDs for 17 day and then received a dose of $3000 \mathrm{IU}$ eCG had a better synchrony of follicular growth during breeding season (Al-Sobayil, 2008).

In our study, however there was no differences in pregnancy rate in all treated groups detected by $\mathrm{P} 4$ test at 14 days post mating, the rate of early embryonic loss was higher in the second and fourth groups which received eCG than in the first group with received only multivitamins, copper and phosphorus. This may be attributed to multiple follicular development with low quality of developed oocytes under the effect of eCG (Sendag et al., 2008). Generally, the phenomenon of early embryonic loss in dromedary camels, especially after embryo transfer, is relatively high (Karen and Mansour, 2020) and may be attributed to infectious origin (Tibary et al., 2006), low progesterone, managemental and environmental reasons (Ali et al., 2010; Pratap et al., 2012).

\section{CONCLUSIONS}

Ovarian inactivity is one of the widespread infertility problems in dromedary camels in UAE during breeding season, especially in nulliparous females. Using of multivitamins and mineral supplementation for a week followed by injection of $1500 \mathrm{IU}$ eCG or using of intravaginal device CIDR for 10 days followed by injection of 1500 IU eCG are reliable protocols to treat the problem of ovarian inactivity in dromedary camels during breeding season.

\section{ACKNOWLEDGMENTS}

The authors wish to thank the highness of Fujairah Emirate, Sheikh Mohammed bin Hamad Al-Sharqi, for his continuous encouragement during the work on this manuscript. Also, we would like to thank Sheikh Seif bin Mohammad Al-Nahyaan for offering the research facilities to conduct this research work. Finally, deep thanks to Dr. Mohamoud Salama, Dr. Mohamed El-Shazlee and 
Mr. Mohsen Azeem for their technical assistance during conduction of the experiments.

\section{Authors' contributions}

Nabil Mansour: Methodology, investigations, statistical analysis, revision, writing and editing. Aly Karen: Methodology, investigations, statistical analysis, writing and editing.

\section{REFERENCES}

Agarwal, S. P., A. K. Rai and N. D. Khanna. 1997. Induction of sexual activity in female camels during the nonbreeding season. Theriogenology. 47: 591-600.

Ahmed, W. M., H. H. El Khadrawy, E. M. Hanafi, A. R. Abd El Hameed and H. A. Sabra. 2009. Effect of copper deficiency on ovarian activity in Egyptian buffalo-cows. World J. Zool. 4: 1-8.

Ainani, H., M. R. Achaaban, A. Tibary, P. Pevet, V. Simonneaux and K. El Allali. 2018. Environmental and neuroendocrine control of breeding activity in the dromedary camel. Rev. Mar. Sci. Agron. Vét. 6: 143-157.

Ali, A., F. A. Al-Sobayil, M. Tharwat, A. Al-Hawas and A. F. Ahmed. 2010. Causes of infertility in female camels (Camelus dromedarius) in Middle of Saudi Arabia. J. Agric. Vet. Sci. 2: 59-66.

Ali, A., D. Derar, A. Alsharari, A. Alsharari, R. Khalil, T. I. Almundarij, Y. Alboti and F. Al-Sobayil. 2018. Factors affecting reproductive performance in dromedary camel herds in Saudi Arabia. Trop. Anim. Health Prod. 50: 1155-1160.

Ali, A., R. Derer, A. Al-Sobayil, A. Al-Hawas and K. Hassanein. 2015. A retrospective study on clinical findings of 7300 cases (2007-2014) of barren female dromedaries. Theriogenology. 84: 452-456.

Ali, A., E. E. Mehana, A. F. Ahmed, O. El-Tookhy, A. Al-Sobayil and A. Al-Hawas. 2011. Ovarian hydrobursitis in female camels (Camelus dromedarius): Clinical findings, histopathology and fertility after unilateral surgical ablation. Theriogenology. 76: 492-499.

Al-Sobayil, K. 2008. The use of estrus synchronization and timed artificial insemination in dromedary female camels in Saudi Arabia. J. Agric. Vet. Sci. 1: 3-9.

Butler, W. R. and R. D. Smith. 1989. Interrelationships between energy balance and postpartum reproductive function in dairy cattle. J. Dairy Sci. 72: 767-783.

Elias, E., E. Bedrak and D. Cohen. 1985. Induction of oestrus in the camel (Camelus dromedarius) during seasonal anestrus. J. Reprod. Fertil. 74: 519-525.

Gherissi, D. E., Z. Bouzebda, F. Bouzebda-Afri, F. Chacha, R. Lamraoui, A. Gherissi and A. L. Miloud. 2020. Ecophysiology of camel ovarian functioning under extremely arid conditions in Algeria. EuroMediterr. J. Environ. Integr. 5: 56.

Hegazy, A. A., A. Ali, M. El-Eknah and S. Ismail. 2004. Studies on pituitary-ovarian axis in the female camel with special reference to cystic and inactive ovaries. J. Camel Sci. 1: 16-24.

Kappel, L. C., R. H. Ingraham, E. B. Morgan, L. Zeringue, D. Wilson and D. K. Babcock. 1984. Relationship between fertility and blood glucose and cholesterol concentrations in Holstein cows. Am. J. Vet. Res. 45: 2607-2612.

Karen, A. and N. Mansour. 2020. Factors affecting pregnancy rates and pregnancy losses after embryo transfer in dromedary camels. Anim. Reprod. Sci. 221: 106580.

Kaufmann, B. A. 2005. Reproductive performance of camels (Camelus dromedarius) under pastoral management and its influence on herd improvement. Livest. Prod. Sci. 92: 17-29.

Khalid, A. and F. A. Al-Sobayil. 2008. The use of estrus synchronization and timed artificial insemination in dromedary female camels in Saudi Arabia. J. Agric. Sci. 1: 3-9.

Monaco, D., G. M. Lacalandra, E. E. El-Hassanein, S. Rateb, O. Salama and K. A. El-Bahrawy. 2012. Effect of a controlled intravaginal drug releaser (CIDR) and $\mathrm{GnRH}$ administration on ovarian follicular dynamics of female dromedary camel during seasonal anestrus period. In: $3^{\text {rd }}$ International Conference of the Society of Camelid Research and Development, $29^{\text {th }}$ January to $1^{\text {st }}$ February, Muscat, Sultanate of Oman, pp. 123-124.

Nagy, P., J. Juhasz and U. Wernery. 2005. Incidence of spontaneous ovulation and development of the corpus luteum in non-mated dromedary camel (Camelus dromedarius). Theriogenolgy. 64: 292-304.

Piccoa, S. J., D. E. Rosab, J. P. Anchordoquya, J. M. Anchordoquya, A. Seoanea, G. A. Mattiolib and C. C. Furnusa. 2012. Effects of copper sulphate concentrations during in vitro maturation of bovine oocytes. Theriogenology. 77: 373-381.

Pratap, N., B. M. Manjunatha and S. Al-Bulushi. 2012. Incidence of early pregnancy loss in dromedary camels (Camelus dromedarius). In: Proceedings of the $3^{\text {rd }}$ International Conference of the Society of Camelid Research and Development, $2^{\text {th }}$ January to $1^{\text {st }}$ February, Muscat, Sultanate of Oman, pp. 109-110.

Quzy, I., A. Suhel and G. N. Purohit. 2013. Hormonal management of ovarian activity in breeding camels two months ahead of the natural breeding season. Camel Int. J. Vet. Sci. 1: 37-49.

Saeed, A., I. M. Khan and M. Hussein. 2009. Change in biochemical profile of pregnant camels (Camelus dromedarius) at term. Comp. Clin. Pathol. 19: 139-143.

Sendag, S., Y. Cetin, M. Alan, K. G. Hadeler and H. Niemann. 2008. Effects of eCG and FSH on ovarian response, recovery rate and number and quality of oocytes obtained by ovum pick-up in Holstein cows. Anim. Reprod. Sci. 106: 208-214.

Skidmore, J. A. 2005. Reproduction in dromedary camels: An update. Anim. Reprod. 2: 161-171.

Skidmore, J. A. 2019. The use of some assisted reproductive technologies in old world camelids. Anim. Reprod. Sci. 207: 138-145.

Tibary, A. and A. Anouassi. 1997. Theriogenology in Camelidae: Anatomy, Physiology, Pathology and Artificial Breeding. Acetes Editions, Rebat, Morocco.

Tibary, A. 2004. Infertility in female camelid 2: Causes and treatment. In: Large Animal Proceedings of the North American Veterinary Conference, January $17^{\text {th }}-21^{\text {st }}$, pp. 287-289.

Tibary, A. and A. Anouassi. 2000. Reproductive disorders in the female camelid. In: Skidmore, J. A. and G. P. Adams, (Eds.), Recent Advances in Camelid Reproduction. International Veterinary, information service (IVIS), USA. Available from: https://www.ivis. org/library/recent-advances-camelid-reproduction/reproductivedisorders-female-camelid.

Tibary, A., C. Fite, A. Anouassi and A. Sghiri. 2006. Infectious causes of reproductive loss in camelids. Theriogenology. 66: 633-647.

Zaher, H., H. El-Zahar, S. Al Sharifi and T. Shety. 2017. Alterations in hematological and biochemical parameters affecting the reproductive performance in female camels (Camelus dromedarius). Int. J. Vet. Health Sci. Res. 5: 155-160.

Note: Kindly note your giventable corrections are not cleared. Please highlight the corrections in

PDF for the further process. 